\title{
PERFORATOR FLAP IN PIG EXPERIMENTAL STUDY WITH APPLICATIONS IN RECONSTRUCTIVE SURGERY
}

\author{
Filip ARDELEAN*,MD \\ Bogdan CHIROIU*, MD \\ Professor Alexandru GEORGESCU**, PhD

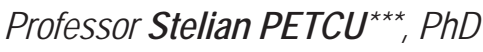

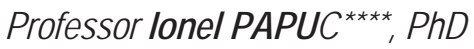 \\ Lecturer Radu LACĂTUŞ ${ }^{\star \star \star \star}$, PhD
}

\begin{abstract}
The emergence of relatively recent date (1982) in the arsenal of methods to cover soft tissue defects, perforator flap quickly reached top choices surgeons from almost all surgical specialties ${ }^{1,2,3}$. Unfortunately not as fast it could move in the direction of understanding and knowledge of physiology and dynamics of such flaps, especially in the venous drainage ${ }^{4}$. Those who practice it are still seeking ways of becoming more efficient preoperative detection of perforator vessels, for finding ways to mitigate the suffering of the vein which, unfortunately, is still quite a few case's.

That's why the creation of experimental models to answer all these requirements was a major concern of specialists. But since there is no perfect animal model similar to human anatomy and physiology generally requires developing more experimental model ${ }^{5-9}$. We aimed to develop an experimental model in pig, the animal relatively less demanding in terms of accommodation and feeding ${ }^{10-13}$, but is an easy omnivorous compared with a real "eating machine" which, because it grows and gain weight very quickly; this is important in terms of experimental and especially in terms of research in the area of flaps, so that they may not be suitable for longer periods of 4-6 weeks. Pig is one of the best experimental animal models, especially for research in the area of flap. Although pigs and humans among numerous differences exist in terms of vascular, reflected especially in the microcirculation, the rest of anatomical characteristics have many similarities to those in the body uman ${ }^{14-16}$.

First, the pig has a skin covered with relatively little hair, pink - so easy to see changes in vascular territory; skin is largely fixed and intimate attachment to the subcutaneous cellular tissue, like the human body. Although the skin is thicker and on average less vascularized and shows some differences in terms of the microcirculation, its vasculature, as the sequence of wound healing processes is also similara1 ${ }^{17,18}$. Among the most obvious differences are: this paniculata carnosus in some regions, namely the trunk; present in the skin and subcutaneous tissue of the more numerous small perforator vessels, except for anterolateral trunk, such that the number of perforator vessels is similar in humans and pigs; the scapular-humeral articulation joints, as in areas adjacent to the anterior and posterior midlines the skin is very mobile and is vascularized by large vessels with a special distribution; contrary to the situation in man, pig superior deep epigastric artery territory is much larger than the inferior deep epigastric artery ${ }^{19-21}$.
\end{abstract}

\footnotetext{
* Clinic Hospital of Recuperation Cluj-Napoca, Deparment of Medical Imaging Radiology

** University of Medicine and Pharmacy "Iuliu Hatieganu" Cluj-Napoca, Department of Plastic Surgery

*** University of Medicine and Pharmacy "Iuliu Hatieganu" Cluj-Napoca, Department of Medical Imaging Radiology

**** University of Agricultural Sciences and Veterinary Medicine Cluj Napoca, Faculty of Veterinary Medicine, Discipline of Semiology, Ethology and Diagnostic Imaging
} 
Considering the above mentioned and the experience of other authors who have developed a number of models of axial flaps (based on internal thoracic penetrating the system, the deep iliac circumflex artery etc.), muscles, musculo-cutaneous flaps, our research team has directed attention to the study of cutaneous and fascio-cutaneous perforator flaps, deepening the results of previous studies and trying to develop new models applicable to humans ${ }^{22-26}$.

Keywords: perforator flap, perforator vessel, skin viability, pig

\section{Material and Methods}

For this study were chosen breed pigs of PIC-BE, sex both male and female, aged 15-16 weeks, weighing 50-55 kg, with a length of 70-80 cm, chest circumference of 70-75 cm and the abdominal of $85-90 \mathrm{~cm}$ and having 14 thoracic vertebrae.

To carry out the study, these experimental groups were created:

- Group I, consisting of 10 animals, which were used to identify the main perforator vessels existing wide body surface and which have been mapped.

- Group II, consisting of 10 animals, which were practiced: • an anterolateral chest skin flap vascularized by a single perforator vessel from intercostal artery; • a lumbar skin flap vascularized by a single perforator vessel; - an external face of the forearm flap vascularized by a single perforator from the radial artery; • a lateral calf flap vascularized by a single perforator vessel from the anterior tibial artery ${ }^{22-24}$. All these flaps were based on one perforator artery, harvested and reinserted in the original area. Choosing perforator vessel which was based flap was dictated by 2 considerations: choosing a central artery in the area and diameter greater choice perforator vessel.

- In the group III were placed in 10 pigs which were applied 2 types of flaps based on perforator artery. The role of this group was to determine the maximum range associated with a perforator artery as the only viable basis of vascularization of skin areas. To achieve these goal two flaps were chosen much larger size than those in group II, namely the external face of the thigh flap and anterolateral chest flap extended.

As group II, the flaps were taken to keep the only source of vascularization of a single perforator by the same considerations as in the lot II. After taking list, these flaps have been reinserted in the donor area and sutured. Also, like group II, pigs entered in the study had similar size which resulted from the collection of relatively similar flaps with areas such easing obtains statistically valid results.

The animals in group I was performed Doppler and arteriography examination in before surgery ${ }^{3}$ using an ultrasound next-generation performance in 2008 GE LOGIQ 9, with high-resolution linear transducers with variable frequency 9 to $14 \mathrm{Mhz}$ and with a GE Voluson ultrasound Expert 7306 Pro with linear transducer with variable frequency 10 to $14 \mathrm{Mhz}$. Perforator vessels detected were mapped, the maps obtained were compared with maps obtained by dissection.

The animals in groups II and III, preoperative Doppler examination was practiced then, starting from the first day after surgery, daily for 14 zile $^{3,27}$. Furthermore, arteriography was performed by injecting the contrast substance in each perforator vessel after one month.

After euthanasia, flaps were detached and examined by Trans lighting. The main clinical parameters seen in the study were: - flap color - flap temperature - the occurrence and progression of areas of necrosis. For each individual animal were made maps of the detected perforator artery surgery and imaging. These were compared among themselves and determine their correspondence. Twodimensional planimetry was determined by the percentage of necrosis appeared in some flaps, and by direct measurement, its distance towards the headquarters artery. 


\section{Parameters followed}

\section{Group I}

Parameters seen in the statistical analysis in group I were as follows: surfaces anatomical regions divided into quadrants of the same size (based on the standard scale), number of perforator vessels in each quadrant (determined by dissection on live anesthetized pigs), number of perforator vessels and distribution on the face of each anatomical region (determined by dissection on live anesthetized pigs).

\section{Group II and Group III}

Were measured for statistical analysis and tracking both groups of study the following parameters: perforator artery location imaging detected (based on division into quadrants according to the standard scale); perforator artery location intraoperatively detected (based on division into quadrants according to the standard scale); minimum distance from the artery to the area of necrosis (if it occurred), local complications of surgery (hematoma, infection, dehiscence) total surface area of necrosis (determined by digital planimetry DicomWorks 1.5.3 program).

Also were determined by calculating the following parameters: total flap area (the weighted sum of the quadrants of the standard scale) viable flap area (total area - area of necrosis) flap viability percentage, minimum viable area in the perforator artery marked (defined as the circle area with the radius of the minimal distance from the area of necrosis to perforator artery).

\section{Intervals and time tracking}

Tracking post operatively flap was made daily for a period of 7 days postoperatively. It was later made tracking every 2-3 days to one month postoperatively, when the animal was slaughtered experience. Flap area was divided into areas of interest represented by concentric circles with center and radius artery kept increasing by $5 \mathrm{~cm}$ from the artery and to the distal edge of the flap.

\section{Flap color and temperature}

Within these areas of interest to do direct observation: flap color (normal, pale, hyperemia and cyanotic) capillary pulse (present, absent, accelerated, slowed down) and identify and track progression of necrosis areas, all these are noted in the tables on the clinical course areas. At the same time and the same areas of interest were made and measurements of skin temperature (determined daily at the same time). This was measured during surgery and 4 times: before flap incision, immediately after incision, after take-off flap and immediately after its reapplication.

\section{Necrosis - appearance, location, extension}

To quantify the final outcomes of groups II and III flap was directly measured area of necrosis occurred on the flap at 1 month after surgery (using the Dicomworks 1.5.3).

\section{Entering data}

\section{Photographic technique}

For photographic support of the research was carried out pictures in these standard conditions: fixed anaesthetized pig on the table operator position lie flat lateral side or lie flat dorsal side of limbs in neutral, the camera set at $150 \mathrm{~cm}$ perpendicular and at $45^{\circ}$ to sagittal plane so that its image and only fully capture the pig and the mass controller, plus use of a field located in the soles disease if the photos 45 degrees; was used multifocus way with 9 points pointing device, to use forced flash (forced on) to equalize the brightness of the exposure. Also, if the need for images, especially in the dissection group and study group to document the uses are summarized below were used non-standard 
exposures accompanied but mandatory inclusion of an item in the camera field of measurement (ruler, surgical marker sized).

\section{Enter data into computer}

Data measurements were integrated into the tracking files pigs, summarized the directory structure and then supplemented with measurements made electronically using the program DICOMWORKS 1.5.3. Data collected from both the mapping study group and from lots of flaps based on perforator vessels were introduced in the Microsoft Excel tables for further statistical processing.

\section{Results}

In the group I, mapping group, have been dissected a total of 4185 of perforator vessels. Number of arteries varied between 408 and 431 vessels / pig examined. Media arteries on the surface of pig $1 / 2$ body was 418.5 vessels, a total area of $4647.5 \mathrm{~cm}^{2}$ is $1 / 2$ body. On average a perforator vascularized $11.1 \mathrm{~cm}^{2}$.

The regions with the constant distribution of the perforator arteries are in order: abdominal area (standard deviation 1.58), distal region of the anterior limb (standard deviation 1.66) and paravertebral lumbar region (standard deviation 1.69). Regions with the greatest variability in the perforator arteries distribution are: thoracic region (standard deviation 5.45) and distal region of the posterior limb (standard deviation 4.72). Regions with the highest frequency of the perforator artery were: posterior limb proximal region (one perforator/7.81 $\mathrm{cm}^{2}$ ) and thoracic region (1 perforator/ $8.16 \mathrm{~cm}^{2}$ ). The regions with the lowest frequency of perforator arteries were: distal region of the posterior limb (one perforator $\left./ 17.32 \mathrm{~cm}^{2}\right)$, cervical region $\left(16.41 \mathrm{~cm}^{2} /\right.$ perforator vessel) and proximal region of the anterior limb (16.11 $\mathrm{cm}^{2} /$ perforator vessel).

All the 20 pigs in group II - lot of qualitative analysis of the perforator flap and group III - group of quantitative analysis of the perforator flap survived the minimum time necessary to further postoperative flap. In the group II, lumbar paravertebral flap presented an average area of 210.45 $\mathrm{cm}^{2}$, an average viability of $93.13 \%$ and a minimum distance perforator vessel - necrosis of 8.25 $\mathrm{cm}$. External face of the anterior limb distal region flap presented an average area of $150.92 \mathrm{~cm}^{2}$, an average viability of $96.25 \%$ and a minimum distance perforator vessel - necrosis of $7.03 \mathrm{~cm}$.

External face of the posterior limb distal region flap (leg) presented an average area of $223.50 \mathrm{~cm}^{2}$, an average viability of $92.94 \%$ and a minimum distance perforator vessels - necrosis of $7.19 \mathrm{~cm}$. Small anterolateral chest flap presented an average area of $161.11 \mathrm{~cm}^{2}$, an average viability of $90.16 \%$ and a minimum distance perforator vessel- necrosis of $8.08 \mathrm{~cm}$. All group II flaps had viable areas for over $90 \%$, demonstrating the viability of the flap harvested exclusively on perforator arteries in experimental pig model.

In the group III, external face of the posterior limb proximal region (thigh) presented an average area of $583.90 \mathrm{~cm}^{2}$, a viability percentage of $69.16 \%$ and an average minimum distance perforator vessel - necrosis of $10.9 \mathrm{~cm}$. Extended anterolateral chest flap presented an average area of $448.81 \mathrm{~cm}^{2}$, a viability percentage of $83.09 \%$ and an average minimum distance perforator vessel - necrosis of 9.59 $\mathrm{cm}$. Group III flaps had a average area of $516.35 \mathrm{~cm}^{2}$ compared to $186.50 \mathrm{~cm}^{2}$ in group II, statistically significant differences. Also, flap viability in group III (76.13\% on average) was significantly lower than the viability of the flap in group II (93.12\% on average). Thus it can be concluded that group III was chosen as a suitable model of quantitative analysis of the perforator flaps.

Flaps in group II had an average viable area of $186.50 \mathrm{~cm}^{2}$. Regions that have been harvested the flaps had an average total of 41.65 perforator vessels / region from which results an average of 12.18 
$\mathrm{cm}^{2}$ area of a perforated vascular integrity in the skin. The results of our study on group II demonstrates that harvesting a flap based only on a perforator package leads to considerable increase the area of perforator vasculature. Dynamic territory of perforator vasculature is significantly greater than within anatomically demonstrating that the perforator flaps are a reliable experimental model in pigs.

The flaps 4 models used to group II: paravertebral lumbar flap, external face of the anterior limb distal region flap, external face of the posterior limb distal region flap, anterolateral chest flap are new experimental models we appropriate qualitative study of the perforator flaps.

Group III flaps were a suitable model for quantitative study of the perforator flaps, because they significantly exceeded the dynamic range of vascularization of a perforator artery, observation demonstrated by the appearance of constant and significant area of skin necrosis (area of necrosis averaged 179, $75.85 \mathrm{~cm}^{2}$ to $97 \mathrm{~cm}^{2}$ that the 2 flaps).

Calculations applied flap in group III shows a minimum distance perforator vessels - necrosis 10, $90 \mathrm{~cm}$ and $9.59 \mathrm{~cm}$ and a minimum viable area for a perforator artery $331.36 \mathrm{~cm}^{2}$. Flaps also had an average viable area of $388.42 \mathrm{~cm}^{2}$. Anatomical area of the vasculature of a perforator artery in regions where the flaps were harvested in group III is an average of $7.98 \mathrm{~cm}^{2}$. Lot III study demonstrates that, in pigs, an area of $331.36 \mathrm{~cm}^{2}$ can be in a predictable vascularized by a single perforator artery. By harvesting a perforator flap, one perforator vessel vascularization area (dynamic range) exceeds the anatomical area of vasculature, one perforator can vascularized territory of over 30 neighboring perforator arteries. External face of the posterior limb proximal region flap and anterolateral extended chest flap represent two new experimental models appropriate quantitative statistical study of the flap.

Perforator flaps in the pig are a valuable experimental model for preclinical studies of the recent methods of coating defects substances. Our study has made, after our knowledge, the first mapping of the anatomy dissection perforator vessels from the entire surface of pig. The study also created 6 new and appropriate experimental models to study perforator flap in pigs.

\section{Conclusions}

It can be said that the perforator flaps made in the study represents a good experimental model for both training and for the degree of survival of a flap based on a single perforator artery, the size of such flaps. In addition, description and practice of new models of perforator flaps increase the scope of such flaps in the experimental field and training. Basically, there are pig skins at a large number of perforator vessels you can behind the creation in future of new experimental models.

\section{References}

1. Georgescu AV, Matei I, Ardelean F, Capota I.: Microsurgical non microvascular flaps in forearm and hand reconstruction. Microsurgery, 207;27:384-394

2. Georgescu AV, Ivan O, Lambeau radial antebrachial en ilot base sur des perforantes distales. A propos d' un cas clinique. Ann.Chir.Plast. Esthet. 2000; 45:58-61

3. Blondeel PN, Beyens G, Verhaeghe R, et al. Doppler flowmetry in the planning of perforator flaps. Br J. Plast. Surg. 1998; 51:2002-2009

4. Kerrigan C., Wizman P., Hjortdal V., Sampalis I.: Global flap ischemia: A comparison of arterial versus venous etiology, Plast. Reconstr.Surg(93), pag.1485.1994.

5. Chvapil M. and Chvapil TA.: Wound Healing Models in Miniature Yucatan Pig. IA:Iowa State University Press. pag.265-288, 1992.

6. Swindle MM. Basic Surgical Exercises Using Swine. Praeger Press, Philadelphia. 1983. 
7. Swindle MM. Surgery, Anesthesia and Experimental Techniques in Swine. Iowa State University Press, Ames. 1998.

8. Swindle MM. Swine as Models in Biomedical Research. Iowa State University Press, Ames. 1992.

9. Wang JF, Olson ME., Reno CR., Wright JB. and Hart DA.: The pig as a model for excisional skin wound healing: characterization of the molecular and cellular biology and bacteriology of the healing process, Comp.Med., 51(4), pag. 341-348.2001.

10.National Research Council. Guide for the Care and Use of Laboratory Animals. National Academiy Press, Washington. 1996.

11.National Research Council. Subcommittee on Swine Nutrition.Nutrient Requirements of Swine. National Academy Press, Washington DC. 1998.

12.Tărăboaţă Gh., Hălmăgean P., Farkas N., Oprescu S.: Tehnologia cresterii suinelor, Editura Didactică si Pedagogică, Bucuresti,1983.

13.Thulin AJ., Brumm MC.: Water: the forgotten nutrient.Swine Nutrition. Butteworth-Heineman, Boston. 1991.

14.Bollen PJA, Hansen AK., Rasmussen HJ.: The Laboratory Swine. FL: CRC Press, Boca Raton. 1999.

15.Bolton LL. Pines E. And Rovee DT.:Wound Healing and Integumentary System. MD:Williams and Wilkins, Baltimore. pag. 1-9, 1988.

16. Holstad, G.E.: The Fetal Pig: An Introduction to the Anatomy of the Fetal Pig. Burgess Publishing Company, Minneapolis, MN. 1959.

17.Field H.E.: The Fetal Pig: An Introduction to Mammalian Anatomy. Stanford University Press CA. 1944.

18.Forbes PD.:Vascular supply of the skin and hair in swine, in Montagna W. and Dobson RL., Advances in Biology of the Skin. Pergamon, New York. 1969.

19. Barone R.: Anatomie comparée des Mammifères domestiques, angiologie. Vigot, Paris. 1996.

20.Papuc I.: Anatomie comparată. Vascularizaţia membrelor la unele mamifere pentadactile, Ed. Gedo, Cluj-Napoca, 2000.

21.Daniel RK., Kerrigan CL.:The omnipotential pig buttock flap, Plast Reconstr Surg (70), pag.11. 1982.

22.Davies AS., Henning M.: Use of swine as a model of musculoskeletal grows in animals. Plenum Press, New York. Pag.839-848, 1986.

23.Kerrigan CL., Zelt RG. Thompson JG. and Diano E.:The pig as an experimental animal in plastic surgery research for the study of skin flaps, myocutaneous flaps and fasciocutaneous flaps. Lab.Anim.Sci. pag.408-412, 1986

24.Sasaki GH. And Pang CY.:Pathophysiology of skin flaps raised on expanded pig skin, Plast. Recontr. Surg. 74(1), pag.59-67. 1984.

25. Mehran RJ. Ricci MA., Graham AM., Carter K. and Smyes JK.: Porcine Model for Vascular Graft Studies, J.Invest.Surg. vol. 4, pag. 37-44.

26.Knight KR., Collopy PA., O’Brien BMcC.: Correlation of viability and laser Doppler Flowmetry in ischemic flaps. Journal of Reconstructive Surgery, (43), pag.444. 1987. 